72 | InterAção

\title{
A NOVA EXTREMA-DIREITA ALEMÃ: POSSÍVEIS DESAFIOS PARA A ALEMANHA E PARA A UNIÃO EUROPEIA
}

Jessica Luciano Gomes ${ }^{1}$

\section{Resumo}

A história contemporânea europeia nos permite avaliar que a emergência de partidos de extrema-direita causa preocupação e temor, tanto nos tomadores de decisão, quanto na sociedade civil. Apesar disso, eles funcionam na legalidade, e tentativas de coibir seu funcionamento fracassaram. Graves crises financeiras, como as que a Europa tem passado, podem proliferar o sentimento xenófobo e racista, fazendo com que os grupos que preguem essas ideologias tenham mais espaço e voz. Este trabalho tem por objetivo compreender as principais características dos partidos de extrema direita na Europa, ao mesmo tempo em que analisa os partidos dessa vertente na Alemanha. $\mathrm{O}$ artigo questiona, também, se dois partidos criados recentemente no país podem ser classificados como de extrema direita.

Palavras-chave: Extrema direita. Alemanha. Europa.

\begin{abstract}
The contemporary European history allows us to evaluate that the emergence of rightwing parties can cause concern and fear in both the decision makers, as well in civil society. Nevertheless, they are legal, and attempts to curb its operation have failed. Severe financial crises such as the one Europe has passed can proliferate the xenophobic and racist sentiment, causing the groups that preach these ideologies to have more space and voice. This study aims to understand the main characteristics of the far-right parties in Europe, while analyzing the parties of this school in Germany. The article raises the question if two parties recently created in the country can be classified as belonging to the extreme right family.
\end{abstract}

Key-words: Extreme right. Germany. Europe.

1 E-mail: gomesjessica89@gmail.com; CV Lattes: <http://lattes.cnpq.br/1409582953503950>. 
73 | InterAção

\section{INTRODUÇÃO}

Frequentemente, notamos a divisão de partidos políticos entre os de "direita" e os de "esquerda", como se essa separação fosse binária e estática. Tradicionalmente, a direita caracterizava-se pela oposição aos preceitos defendidos pós-Revolução Francesa, ao socialismo e ao Marxismo. Entretanto, há várias "direitas" e várias "esquerdas", que apresentam muitas distinções

entre si. Com isso, podemos classificar a extrema direita como partidos que defendem a extrapolação de idéias nacionalistas, conservadoras e xenófobas (COLE, 2005).

A emergência de partidos de extrema direita não é um fenômeno novo. A literatura especializada demonstra que suas causas retomam à alteração da conjuntura econômica e social nos anos 1980, conjugada às noções de pósmaterialismo. Atrelada a isso estava a falta de credibilidade dos eleitores nos partidos existentes, no sistema político e nas instituições (BETZ, 1993; IGNAZI 1992,1995; TOSTES, 2009,2011).

Este presente trabalho se propõe a entender, de modo geral, as características dos partidos de extrema direita e, em particular, a atuação desses partidos na Alemanha. O país foi escolhido por ter vivenciado as consequências de um partido que levou os ideais de nacionalismo e xenofobia às últimas consequências, e onde ainda há grupos que se alimentam desse passado. Outra razão para tal escolha se deve ao fato de que a Alemanha faz parte do núcleoduro da União Europeia, e um possível aumento de partidos de extrema direita no país poderia desafiar aspectos da integração do bloco.

$\mathrm{O}$ artigo pretende ainda entender o surgimento de dois novos partidos na Alemanha, o Alternative für Deutschland (Alternativa para a Alemanha), 
74 | InterAção

criado em 2013, e o Die Rechte (A Direita), fundado em 2012. Serão levados em consideração os pré-requisitos utilizados por Ignazi (1992) para a classificação de partidos de extrema direita. O trabalho questionará se esses dois novos partidos poderão ser classificados sob essa denominação e se eles poderão, de alguma forma, desafiar pontos importantes da União Européia, como a integração financeira e as instituições comunitárias.

A metodologia utilizada por esse artigo consiste na revisão bibliográfica dos principais trabalhos acerca da atuação dos partidos de extrema-direita na Europa, como também na análise de manifestos dos partidos, discursos e declarações de seus líderes, reportagens e notas na mídia (alemã e europeia).

A primeira seção se dedica à compreensão do surgimento e das motivações de partidos de extrema direita (I). A segunda seção analisa tradicionais partidos de extrema direita alemães, como o Nationaldemokratische Partei Deutschlands (Partido Nacional Democrata da Alemanha), o Die Republikaner (Os Republicanos) e o Deutsche Volksunion (União Alemã do Povo) (II). A terceira seção analisa o surgimento de dois novos partidos no cenário político alemão (III), e a quarta seção questiona se os mesmos poderiam ser considerados como de extrema direita (IV). A título de conclusão, o trabalho avalia se eles podem desafiar algum ponto-chave da política alemã e européia $(\mathrm{V})$.

\section{0 SURGIMENTO DE PARTIDOS DE EXTREMA-DIREITA, SUAS MOTIVAÇÕES E COMPORTAMENTOS}

De acordo com Rydgren (2005), no pós-Segunda Guerra Mundial, os partidos de extrema direita ficaram à margem no cenário político europeu, 
75 | InterAção

devido aos acontecimentos desastrosos causados pelo conflito. Porém, segundo Ignazi (1995), o ambiente europeu da década de 1980, caracterizado pela mudança econômica e social, pela desconfiança de parte do eleitorado nas instituições e nos partidos existentes e pelo aumento do sentimento de individualismo, criou um terreno fértil para o surgimento de partidos de extrema direita. Para Jackman e Volpert (1996), o aumento do desemprego também foi um forte componente para a proliferação desses partidos.

Atrelados a isso, os partidos de extrema direita advogam pela diminuição da influência do Estado, dos impostos e de programas sociais. Eles têm, assim, uma visão neoliberal, que “[...] é uma arma política contra as instituições políticas estabelecidas e sua alegada monopolização do poder político, o qual trava o progresso econômico e suprime a verdadeira democracia" (BETZ, 1993:418).

Os partidos de extrema direita se diferenciam dos demais pela oposição ao status quo social, político e cultural e pela defesa das liberdades individuais (BETZ, 1993). É preciso diferenciar, contudo, essa nova extrema direita, que surgiu nos anos 1980 e foi resultante do pós-industrialismo, daquela de orientação tradicional, que se espelhava em regimes fascistas (BETZ, 1994; IGNAZI, 2003 apud TOSTES, 2009).

Estudos mostram que o perfil dos eleitores dos partidos de extrema direita é, geralmente, caracterizado por desempregados, por indivíduos com menor renda e com menor acesso à educação formal (LUBBERS et al., 2002). Há, também, número maior de homens e de jovens (BETZ, 1994; GIVENS, 2004; LUBBERS et al., 2002; IGNAZI, 2003 apud KESSLER et al., 2005). Mas, de acordo com Ignazi (1992:05), os partidos de extrema direita têm a “[...] peculiaridade que consiste em sua capacidade de mobilizar votos de todas as camadas sociais e de todos os alinhamentos políticos anteriores". 
76 | InterAção

Os indivíduos que votam em partidos de extrema direita, geralmente, não tiveram seus anseios resolvidos pelos partidos tradicionais e, com isso, a extrema direita tem a oportunidade de "ganhar vantagem por meio da política de ressentimento" (KESSLER; FREEMAN, 2005:263). Principalmente em países de grande imigração - como é o caso da Alemanha -, muitos indivíduos ainda votam em partidos de extrema direita por conta da mentalidade de que os estrangeiros são os responsáveis pela crise econômica e social (BETZ, 1994 apud KESSLER; FREEMAN, 2005).

Ainda que os partidos de extrema direita tenham obtido, nos últimos anos, pequena parcela da quantidade de votos, deve-se atentar ao papel que eles exercem, que é o de "influenciar o comportamento de partidos maiores e mais estabelecidos", já que a "[...] fragmentação (o número de partidos num sistema partidário) e a polarização do sistema de partidos (a proporção de cadeiras legislativas que os partidos extremistas detêm) foram identificados como fatores que minam a estabilidade política" (JACKMAN, VOLPERT 1996:503).

Portanto, mesmo que partidos de extrema direita não tenham ampla aceitação do eleitorado ou que por ora não tenham obtido grande representação parlamentar, não se deve ignorá-los, pois são capazes de descompor o tradicional cenário político. Deve-se atentar, principalmente, àqueles que inflamam discursos de ódio contra minorias ou grupos étnicos - tais discursos tornam-se perigosos em uma sociedade europeia multicultural. 
77 | InterAção

\section{OS PRINCIPAIS PARTIDOS DE EXTREMA-DIREITA NA ALEMANHA}

Esta seção preocupa-se em mapear os principais partidos de extrema direita que fazem parte do cenário político alemão. Tomamos como base aqueles que já foram classificados como tal pela literatura (IGNAZI, 1992,1995), os manifestos do partido e declarações de seus líderes na mídia.

É necessário entender os mecanismos de sustentação desses partidos, já que a Alemanha tem um histórico de um regime totalitário que fez do ódio racial e da xenofobia uma política de Estado. É importante salientar, contudo, que alguns partidos de extrema direita alemães não têm ligações com o nazismo, apesar de muitos terem discursos de ódio contra minorias.

Um acontecimento recente no país poderá influenciar a atuação dos partidos de orientação extremista: o surgimento do grupo denominado PEGIDA (Patriotische Europäer gegen die Islamisierung des Abendlandes - Europeus Patriotas Contra a Islamização do Ocidente). O movimento defende a proteção de "valores ocidentais (democráticos e cristãos)" e, segundo seus líderes, a interrupção da "islamização" da Alemanha. O grupo organizou, em 2014, alguns protestos pelo país, e o maior deles, na cidade de Dresden, contou com a presença de vinte e cinco mil pessoas (BRADY, 2015). Muito se questiona a respeito da possibilidade de haver alianças entre o PEGIDA e partidos de extrema-direita, já que eles têm em comum o forte componente anti-imigratório. Por ora, não houve o alinhamento entre o grupo e partidos políticos. Entretanto, o PEGIDA é um componente importante no estudo do extremismo político na Alemanha, por seu discurso inflamado e pelo número expressivo de pessoas que fazem parte de seus protestos. 
78 | InterAção

\subsection{Nationaldemokratische Partei Deutschlands (Partido Nacional Democrata da Alemanha)}

O Nationaldemokratische Partei Deutschlands (NPD) foi criado em 1964 em Hannover, formado por membros de partidos de orientação nazista, como o Deutsche Reichspartei, e por outros grupos nacionalistas. A princípio, o grupo não tinha orientação de extrema direita, e advogava pela saída das tropas estrangeiras do solo alemão e pela reunificação do país. Contudo, nos anos 1970, o partido passou por uma reestruturação, e o viés extremista ganhou espaço (NATIONAL DEMOCRATIC PARTY OF GERMANY, 2014).

Atualmente, o NPD defende, principalmente, o fim da imigração em massa, e tem forte caráter anti-islâmico. No manifesto do partido, argumenta-se que existe uma correlação entre o aumento da violência e o acréscimo da imigração de muçulmanos. Segundo eles, a integração traz um "alto custo" para a sociedade alemã, e que pode comprometer "a paz e o futuro social" do país já que, segundo eles, estrangeiros menos qualificados detém postos de trabalho, enquanto alemães com boa qualificação estão sem emprego. O NPD é a favor, também, da diminuição do número de asilados e refugiados no país (NATIONALDEMOKRATISCHE PARTEI DEUTSCHLAND, 2014).

Houve algumas tentativas de banir o partido - todas sem sucesso (STEUDEL, 2014). Apesar disso, o NPD funciona na legalidade, pois a Constituição alemã garante no artigo $21 \S 1$ que "Os partidos colaboram na formação da vontade política do povo. A sua fundação é livre. A sua organização interna tem de ser condizente com os princípios democráticos" (REPÚBLICA FEDERAL DA ALEMANHA, 2014). Esse ponto é muito importante para que entendamos a atuação dos partidos de extrema direita na Alemanha: o país, por ter um histórico de totalitarismo, defende amplamente a 
79 | InterAção

democracia - mesmo que isso represente a existência de um partido nãodemocrático.

Entretanto, as tentativas de tornar a atuação do NPD ilegal baseiam-se no §2 do mesmo artigo, que define que "são inconstitucionais os partidos que, pelos seus objetivos ou pelas atitudes dos seus adeptos, tentarem prejudicar ou eliminar a ordem fundamental livre e democrática ou por em perigo a existência da República Federal da Alemanha". Para que seja banido, deve ser comprovado que o NPD faz uso da violência como meio de desafiar a democracia. Isso é, todavia, difícil de ser comprovado, já que o NPD tem poucos membros e pequena parcela do número de votos (CROSSLAND, 2013).

Em 2012, o NPD contava com 6000 membros. No ano seguinte, esse número caiu para 5500. Dificuldades econômicas, polêmicas envolvendo seus líderes e as várias tentativas de tirá-lo da legalidade contribuíram para o enfraquecimento da atuação do partido (BUNDESAMT FÜR VERFASSUNGSSCHUTZ, 2013).

Nas eleições para o Parlamento alemão (Bundestag) de 2013, o NPD obteve 1.3\% dos votos (DEUTSCHER BUNDESTAG, 2014). Esses números, ao longo dos anos, não foram expressivos. O maior índice conquistado, de $4.3 \%$, ocorreu em 1969; e o menor, 0.2\%, repetiu-se nos anos de 1980 e 1983. O NPD nunca conquistou uma cadeira no Parlamento (WAHLRECHT, 2014), mas conseguiu obter representação local, nos conselhos distritais e nas câmaras municipais (MINKENBERG, 1992). Nas eleições de 2014 ao Parlamento Europeu, o NPD conquistou 1\% dos votos, que lhe deu direito a um assento na instituição (PARLAMENTO EUROPEU, 2014), e que ficou a cargo de Udo Voigt, líder do partido e que já declarou considerar Hitler como "um grande estadista" (ADEKOYA et al, 2014). 
80 | InterAção

\subsection{Die Republikaner(Os Republicanos)}

O Die Republikaner (REP) foi fundado em 1983 em Munique. As propostas iniciais do partido se baseavam na extinção de sindicatos, no fim da imigração e na volta às fronteiras alemãs do pré-Segunda Guerra Mundial (ATKINS, 2004).

O REP conquistou grande eleitorado na década de 1980, atingindo 7.5\% dos votos em eleições municipais (BETZ, 1993). Apesar disto, nunca conquistou um assento no Parlamento alemão, e o maior índice nas eleições nacionais ocorreu em 1990, com 2.1\% dos votos (WAHLRECHT, 2014).

O REP mostra-se contrário à integração européia, e advoga pela saída do país da zona do Euro (DIE REPUBLIKANER, 2014). Nas eleições de 2009 ao Parlamento Europeu, o partido conquistou 1.3\% dos votos, o que não lhe garantiu representação na Casa. O mesmo aconteceu nas eleições de 2014, nas quais o REP obteve $0.4 \%$ dos votos (PARLAMENTO EUROPEU, 2014).

De acordo com Mudde (2000:38), o REP atua de forma paradoxal. Ele tenta se afastar de outros partidos de extrema direita (que o autor chama de "partidos contaminados"), ao mesmo tempo em que outros partidos tradicionais não querem se aliar ao REP e serem por ele "contaminados". Com isso, o REP atua de forma marginal e, de certa forma, desvanecida.

\subsection{Deutsche Volksunion (União Alemã do Povo)}

O Deutsche Volksunion (DVU) foi fundado em 1971 por Gerhard Frey, magnata do ramo de publicações. Após vários incentivos financeiros por meio de seu fundador, o partido obteve sucesso nas eleições locais, sendo "em vinte 
81 InterAção

anos, o primeiro partido de extrema direita a obter um assento numa assembléia legislativa" (MUDDE, 2000:62).

Sua trajetória pode ser considerada instável, já que alterna períodos de relativo sucesso seguido por colapsos. Durante os anos 1980 e 1990, o DVU conquistou representação em níveis locais e regionais. Entretanto, crises financeiras e diminuição no número de filiados resultaram em tensões dentro do partido. Ele conseguiu, apesar disso, manter-se no jogo político alemão, ao conquistar cadeiras em representações estaduais, mas nunca chegou ao Bundestag (MUDDE, 2000).

Como Mudde (2000:64) argumenta, o DVU é um “partido fantasma”. Ao mesmo tempo em que tinha grande número de filiados (em 1992, esse número era de mais de vinte e seis mil membros), era difícil para o DVU manter uma estrutura organizacional perene e articular coalizões com outros partidos de mesma orientação. Em 2011, o partido foi desfeito, e a estrutura remanescente unificou-se ao NPD (REISSMANN, 2011).

\section{0 NOVO CENÁRIO POLÍTICO ALEMÃO}

Dois partidos que surgiram nos últimos anos no cenário político alemão têm atraído muita atenção da mídia: o Alternative für Deutschland (Alternativa para a Alemanha - AfD) e o Die Rechte (A Direita - DR). Por ainda não terem sido classificados pela literatura especializada, este presente trabalho se propôs a fazê-lo utilizando os critérios de Ignazi (1992). Com isso, cabem as seguintes perguntas: qual seriam as orientações políticas do AfD e da DR? Eles poderiam ser considerados de extrema direita? Eles poderiam desafiar pontos-chave da 
82 | InterAção

atual conjuntura política alemã, ou até mesmo do processo europeu de integração?

Para responder a esses questionamentos, serão levados em consideração os manifestos dos partidos, discursos e declarações de seus líderes e notícias em veículos de comunicação.

\subsection{Alternative für Deutschland(Alternativa para a Alemanha)}

O AfD foi criado em 2013 e, de acordo com o próprio partido, é formado por "cidadãos, e não por políticos profissionais" (ALTERNATIVE FÜR DEUTSCHLAND, 2014b). Segundo seu manifesto, ele foi concebido como uma "reação" às falhas dos políticos em gerenciar a crise do euro e suas consequências. E com ela houve uma "renúncia dos fundamentos éticos, que são constitutivos de uma ordem livre e democrática". Para eles, a democracia, o Estado de direito e a separação de poderes sucumbiram como consequência da crise do Euro. O partido quer, com isso, "trazer de volta o princípio da responsabilidade, da solidariedade, da transparência e da sustentabilidade" (ALTERNATIVE FÜR DEUTSCHLAND, 2014a).

O foco do AfD é, portanto, a reorganização econômica da Alemanha e a saída do país da zona do Euro. O partido também se expressa em outros temas, como imigração - são a favor, mas os imigrantes não poderiam receber benefícios governamentais -, da proteção da família - formada, preferencialmente, por um casal heterossexual -, e a preservação do meio ambiente. São favoráveis à proteção a asilados e a refugiados, desde que respeitada a atual legislação acerca do tema (ALTERNATIVE FÜR DEUTSCHLAND, 2014a). Pode-se inferir, com isso, que o AfD seria contrário 
83 | InterAção

ao aumento do escopo de proteção legal e financeira aos refugiados, debate que está em voga na Alemanha.

Nas eleições de 2013 ao Bundestag, o AfD conseguiu 4.7\% dos votos, o que não lhe deu direito a representação parlamentar (WAHLRECHT, 2014). Nas eleições de 2014 aos parlamentos estaduais, o AfD conquistou 10\% dos votos, o que lhe permitiu a representação política na região da Saxônia - cuja capital é a cidade de Dresden, local que recebe grande número de refugiados e onde o movimento PEGIDA é mais atuante -, e na região de Hamburgo, onde o partido conseguiu 5,5\% dos votos, o que lhe garantiu sete cadeiras no parlamento estadual (DEUTSCHE WELLE, 2014; 2015).

Pode-se perceber a crescente participação do AfD no cenário político alemão, há dois anos de sua criação. Contudo, o aumento de sua expressividade em uma área que recebeu grandes protestos anti-imigração e anti-islamização, como a cidade de Dresden, poderia ser um indício da legitimação desses protestos por parte do eleitorado. Apesar de manterem conversas e afirmarem ter pontos em comum (como a reforma da lei imigratória), o AfD afirmou que não cooperará ou formará alianças com o PEGIDA (CONRAD, 2015).

Nas eleições de 2014 ao Parlamento Europeu, o AfD conquistou 7.10\% dos votos - o que permitiu ao partido obter sete cadeiras na instituição (PARLAMENTO EUROPEU, 2014). O AfD deixa claro, porém, que não é eurocético; é apenas contrário à zona do Euro (MCGUINNESS, 2014). No Parlamento Europeu, os partidos não se agrupam por nacionalidade, mas sim por orientação política. O AfD faz parte do Grupo dos Conservadores e Reformistas Europeus, criado em 2009 e o terceiro maior da instituição, e que se denomina como "euro-realista": segundo essa visão, o Grupo pretende “deslocar a UE da marcha ideológica em direção a um super-Estado federal 
84 | InterAção

europeu e conduzi-la a uma organização mais flexível" (EUROPEAN CONSERVATIVES AND REFORMISTS GROUP, 2015).

\subsection{Die Rechte (A Direita)}

O Die Rechte (DR) foi fundado em 2012 e naquele ano contava com 150 membros. No ano seguinte, esse número atingiu a marca de 500 membros - e a maior parte deles tem relação com o neo-nazismo (BUNDESAMT FÜR VERFASSUNGSSCHUTZ, 2013).

O primeiro ponto abordado pelo manifesto do partido é a "manutenção da identidade" alemã que, para eles, deve ser "mantida no século XXI". Eles pleiteiam a proteção da língua alemã contra estrangeirismos e, principalmente, contra anglicismos. A cultura alemã, para eles, também deve ser preservada contra "influências estrangeiras", de maneira que a publicidade em língua estrangeira seja proibida. O manifesto, além disso, propõe a "revogação da tolerância a estrangeiros" e o estreitamento das leis para refúgio e a proibição de adoção de crianças por casais homossexuais (DIE RECHTE, 2014).

Muito se questiona a respeito dos rumos do partido e se ele poderia ser um grande concorrente ao NPD. Acredita-se que o DR teria um viés mais radical, dado o passado de seu líder e fundador, Christian Worch, com o movimento neonazista (WITTROCK et al, 2012). O DR possui poucos membros e atua localmente, o que indicaria um desempenho modesto no cenário político alemão. O partido conseguiu um assento nas eleições locais da cidade de Dortmund, sendo representado por Siegfried Borchardt - que renunciou ao cargo em meio ao grande número de protestos contra o partido (DER SPIEGEL, 2014). 
85 | InterAção

O partido Die Rechte tem, claramente, uma atuação menor que o Alternative für Deutschland. Uma das possíveis explicações seria que o primeiro tem forte caráter xenófobo e é aliado ao movimento neo-nazista, enquanto o segundo, apesar de radical, tem o foco na zona do Euro e na política de integração europeia.

\section{UMA POSSÍVEL NOVA EXTREMA-DIREITA?}

Ignazi (1992) delimitou três critérios principais para a classificação de partidos como de extrema direita. $O$ primeiro deles diz respeito ao posicionamento do partido no espectro político; o segundo está relacionado aos aspectos ideológicos partidários e se o mesmo faz alguma referência à ideologia fascista; o terceiro é definido pela atitude anti-sistêmica do partido. De acordo com essas classificações, poderia o Die Rechte (DR) e o Alternative für Deutschland (AfD) ser considerados como de extrema direita?

Quanto ao primeiro critério, o DR é, claramente, um partido de direta, pois o próprio nome do partido deixa isso evidente. O AfD não deixa clara sua orientação no espectro político, porém se pode afirmar que está mais à direita, pois são conservadores em temas sociais e liberais em temas econômicos.

Em relação ao segundo critério, o DR tem afinidades com o regime nazista, já que Worch fez parte do movimento neo-nazista (WILDE, 2012). Quanto ao AfD, não se pode afirmar que haja qualquer ligação com ideologias nazifascistas.

O terceiro critério caracteriza o partido quanto ao seu posicionamento anti-sistêmico. De acordo com Ignazi (1992:12), 
86 | InterAção

[...] partidos de extrema direita dividem algumas características comuns que são claramente anti-sistêmicas. Elas incluem antiparlamentarismo, antipluralismo e antipartidarismo. Mesmo que tais partidos não advoguem abertamente um sistema institucional não-democratico, eles de qualquer forma minam a legitimidade do sistema ao expressar desconfiança no sistema parlamentarista, [...] excesso de liberdade, fraqueza do Estado $[\ldots]$

O DR é o que parece estar mais contrário ao status quo político na Alemanha. O manifesto do partido prega que haja um fim para o "excesso de oferta de deputados no Parlamento". O partido insta, também, que haja eleições diretas para presidente e para juízes do Tribunal Constitucional Federal (DIE RECHTE, 2014).

Tomando como base as classificações delineadas por Ignazi (1992), podemos concluir o AfD não poderia ser considerado como de extrema direita, já que ele é claramente contrário à zona do Euro, mas não propõe nenhuma mudança sistêmica e não é ligado a ideologias de cunho totalitário. Possivelmente, o AfD poderia ser classificado como um partido de direita radical. Portanto, somente o partido Die Rechte se enquadraria como de extrema direita segundo a categorização proposta pelo autor, pois o partido advoga grandes mudanças no sistema político e democrático alemão, além de fazer referência à ideologia nazista.

Como esses dois partidos foram criados recentemente, ainda é cedo para especular se eles seriam capazes de alterar o quadro político e partidário alemão. Contudo, é certo que até mesmo partidos tradicionais (como o União Democrática Cristã - CDU -, o Partido Social Democrata - SPD - e o Partido Democrático Liberal - FDP) presenciaram alterações substanciais nos últimos anos. Nas eleições ao parlamento federal de 2013, o CDU (partido de Angela Merkel) conquistou a maioria dos assentos, seguido pelo SPD, e o FDP não conseguiu os 5\% mínimos necessários (THE ECONOMIST, 2013). Já nas 
87 | InterAção

eleições regionais de 2015, o CDU apresentou forte queda no total de votos na região de Hamburgo, um dos centros mais importantes do país: de $21.9 \%$ em 2011 para 15.9\%. O FDP, um dos partidos mais atuantes do pós-guerra, apresentou um dos resultados mais pífios, de $7.4 \%$ dos votos (THE ECONOMIST, 2015).

Além disso, o cenário político alemão tem apresentado polaridade dúbia em relação a anos anteriores. Segundo a revista The Economist (2015), as tentativas da chanceler alemã em "modernizar" seu partido acabaram aproximando-o da esquerda (representada principalmente pelo SPD). Com isso, segundo o semanário, o eleitor se confunde, pois aqueles que se inclinam à direita acabam votando em partidos como o AfD e o FDP. Ademais, o comparecimento do eleitorado alemão às urnas vem caindo nos últimos anos. De acordo com Rossteutscher et al (2014:02), isso pode ser explicado pelo eleitorado crescentemente diverso, que não mais se atém à "lealdade partidária" e que substitui suas "ligações sociais e ideológicas".

O termo "extrema-direita" é sensível à população alemã, pelo próprio passado do país. Assim, um partido que se intitula como sendo dessa vertente traz à memória um histórico de guerra, dor e segregação. Nem mesmo o Die Rechte, que apresenta um manifesto xenófobo, islamofóbico e homofóbico se designa dessa maneira. Entretanto, sua ideologia, seu programa e suas ações devem importar mais que seu próprio nome.

\section{CONSIDERAÇÕES FINAIS}

Apesar de muitos partidos de extrema direita não conquistarem alta porcentagem de votos ou representação em seus respectivos parlamentos, eles 
88 | InterAção

são responsáveis pela mudança no tradicional cenário político. Muitos indivíduos que não tiveram seus anseios atendidos pelos partidos do establishment se sentem representados por partidos extremistas. Entretanto, o discurso de ódio a estrangeiros e minorias étnicas propagado por muitos desses partidos deve ser monitorado, principalmente num continente que recebe anualmente milhares de imigrantes.

No caso da Alemanha, esse monitoramento deve ser ainda maior, já que grupos neonazistas ainda persistem. Por ser um regime democrático, partidos de extrema direita funcionam legalmente no país - a não ser que façam uso da violência como forma de atingir seus objetivos. Como ficou demonstrado nesse artigo, há um novo partido alemão de extrema direita - o Die Rechte - que, apesar de ainda conter com poucos membros e de atuar localmente, tem um discurso intenso. Deve-se atentar aos possíveis aumentos de filiados ou de número de votos, já que a população alemã (e europeia) sofreu duramente as consequências de um partido extremista no poder.

No caso do Alternative für Deutschland, que esse trabalho demonstrou não configurar como sendo de extrema direita, o espaço para atuação é um pouco mais amplo. O partido advoga pelo fim da zona do Euro em um dos países que pertencem ao núcleo-duro da União Européia. Para a Alemanha, sair da zona do Euro poderia significar um retrocesso na trajetória de integração por ela almejada e financiada. Uma possível saída do país da zona do Euro poderia resultar, ainda, numa menor influência no bloco, algo impensável para países como França e Alemanha. O Alternative für Deutschland conquistou sete cadeiras no Parlamento Europeu logo em sua primeira campanha, e tem sido atraente para os eleitores que não mais se sentem representados pela direita tradicional alemã. As possibilidades para esse partido ainda são restritas, mas um pouco mais otimistas. 
89 | InterAção

\section{REFERÊNCIAS}

ADEKOYA, Remi; SMITH, Helena; DAVIES, Lizzy; PENKETH, Anne; OLTERMANN, Philip. Meet the new faces ready to sweep into the European parliament. The Guardian. 26 de maio de 2014. Disponível em http:/ / www.theguardian.com/world/2014/may/26/meet-the-new-faces-inthe-european-parliament. Acesso em 05 de dezembro de 2014.

ALTERNATIVE FÜR DEUTSCHLAND (a). "Political Guidelines of the Alternative für Deutschland (AfD)". Disponível em https://www.alternativefuer.de/wp-content/uploads/2014/06/PoliticalGuiding-Principles-AfD.pdf. Acesso em 10 de dezembro de 2014.

ALTERNATIVE FÜR DEUTSCHLAND (b). “Wer ist die AfD?" Disponível em http://www.alternativefuer.de/programm-hintergrund/mut-zurwahrheit/wer-ist-die-afd/. Acesso em 10 de dezembro de 2014.

ATKINS, Stephen E. Encyclopedia of Modern Worldwide Extremists and Extremist Groups. Greenwood Publishing Group, p.273-274, 2004.

BETZ, Hans-Georg. Radical Right-Wing Populism in Western Europe. New York, St. Martin's Press, 1994 apud TOSTES, Ana Paula. Razões da Intolerância na Europa Integrada.

DADOS - Revista de Ciências Sociais, Rio de Janeiro, vol. 52, no.2, p.337, 2009.

BETZ, Hans-George. The New Politics of Resentment Radical Right-Wing Populist Parties in Western Europe. Comparative Politics, vol.25, no.4, p.413427, 1993.

BRADY, Kate. Record turnout at Dresden PEGIDA rally sees more than $\mathbf{2 5 , 0 0 0}$ march. Deutsche Welle, 12/01/2015. Disponível em

http:/ / www.dw.de/ record-turnout-at-dresden-pegida-rally-sees-more-than25000-march/a-18186820. Acesso em 02 de abril de 2015.

BUNDESAMT FÜR VERFASSUNGSSCHUTZ. “2013 Annual Report on the Protection of the Constitution - Facts and Trends". Disponível em file:/ / C:/Users/USER/Downloads/ annual-report-2013-summary.pdf. Acesso em 05 de dezembro de 2014.

COLE, Alexandra. Old right or new right? The ideological positioning of parties of the far right. European Journal of Political Research, no. 44, p.203-230, 2005. 
90 | InterAção

CONRAD, Naomi. German populist groups AfD, Pegida look for common ground. Deustche Welle, 08/01/2015. Disponível em

http://www.dw.de/german-populist-groups-afd-pegida-look-for-commonground/a-18180581. Acesso em 01 de abril de 2015.

CROSSLAND, David. NPD Ban Bid: Germany's Risky Push to Outlaw FarRight Party. Spiegel Online. 03 de dezembro de 2013. Disponível em http:// www.spiegel.de/international/germany/germany-launches-new-bidto-outlaw-far-right-npd-party-a-937008.html. Acesso em 12 de dezembro de 2014.

DER SPIEGEL. "Die Rechte"-Kandidat im Dortmunder Stadtrat: "SS-Siggi" gibt sein Mandat ab.04/07/2014. Disponível em http:/ / www.spiegel.de/politik/ deutschland/siegfried-borchardt-ss-siggi-gibtmandat-in-dortmunds-stadtrat-auf-a-979241.html. Acesso em 02 de abril de 2015.

DEUTSCHE WELLE. 31/08/14. German anti-euro party enters state parliament in Saxony elections. Disponível em http:/ / www.dw.de/germananti-euro-party-enters-state-parliament-in-saxony-elections/a-17891812. Acesso em 01 de abril de 2015.

DEUTSCHE WELLE. 15/02/15. SPD takes Hamburg elections, AfD gets first seat in Western state parliament. Disponível em http:/ / www.dw.de/spdtakes-hamburg-elections-afd-gets-first-seat-in-western-state-parliament/a18259541. Acesso em 01 de abril de 2015.

DEUTSCHER BUNDESTAG. CDU/CSU bleibt größte Fraktion im Bundestag. Disponível em

http://www.bundestag.de/bundestag/wahlen/wahlergebnisse_2013/213818. Acesso em 05 de dezembro de 2014.

DIE RECHTE. “Programm der Partei DIE RECHTE”. Disponível em http:/ / worch.info/die-rechte/pdf/Parteiprogramm.pdf. Acesso em 10 de dezembro de 2014.

DIE REPUBLIKANER. “30 Schwerpunkte. Wahlprogramm 2013”. Disponível em http://rep.de/upload/CMS/PDF/130413_rep_BY_wahlprogramm_s.pdf. Acesso em 05 de dezembro de 2014.

EUROPEAN CONSERVATIVES AND REFORMISTS GROUP. “About the ECR group". Disponível em http://ecrgroup.eu/about-us/the-ecr-in-the-europeanparliament/. Acesso em 01 de abril de 2015. 
91 | InterAção

GIVENS, Terri. The Radical Right Gender Gap, Comparative Political Studies, no.37, p.30-54, 2004 apud KESSLER, Alan E.; FREEMAN, Gary P. Support for Extreme Right-Wing Parties in Western Europe: Individual Attributes, Political Attitudes, and National Context. Comparative European Politics, no.3, p.264, 2005.

IGNAZI, Piero. Extreme Right Parties in Western Europe. Oxford: Oxford University Press, 2003 apud TOSTES, Ana Paula. Razões da Intolerância na Europa Integrada. DADOS - Revista de Ciências Sociais, Rio de Janeiro, vol. 52, no.2, p.337, 2009.

IGNAZI, Piero. The silent counter-revolution - Hypotheses on the emergence of extreme right-wing parties in Europe. European Journal of Political Research, no. 22, p.3-34, 1992.

IGNAZI, Piero. The Re-emergence of the Extreme Right in Europe. Institut für Höhere Studien Reihe Politikwissenschaft, 1995.

JACKMAN, Robert W.; VOLPERT, Karin. Conditions Favouring Parties of the Extreme Right in Western Europe. British Journal of Political Science, vol. 26, no.4, p.501-521, 1996.

KESSLER, Alan E.; FREEMAN, Gary P. Support for Extreme Right-Wing Parties in Western Europe: Individual Attributes, Political Attitudes, and National Context. Comparative European Politics, no.3, p.261-288, 2005.

LUBBERS, Marcel; GJSBERTS, Mérove; SCHEEPERS, Peer. Extreme right-wing voting in Western Europe. European Journal of Political Research, no.41, p.345-378, 2002.

MCGUINNESS, Damien. Germany's Alternative fuer Deutschland shakes up politics. BBC News. 02 de setembro de 2014. Disponível em http://www.bbc.com/news/world-europe-29010588. Acesso em 10 de dezembro de 2014.

MINKENBERG, Michael. The New Right in Germany The transformation of conservatism and the extreme right. European Journal of Political Research, no.22, p.55-81, 1992.

MUDDE, Cas. The Ideology of the Extreme Right. Manchester e Nova Iorque: Manchester University Press, p.31-59, 2000.

NATIONAL DEMOCRATIC PARTY OF GERMANY. "History of the National Democratic Party" Disponível em http:/ / www.npd-

sh.de/sprachen/1\%20\%20english.php. Acesso em 05 de dezembro de 2014. 
92 InterAção

NATIONALDEMOKRATISCHE PARTEI DEUTSCHLAND. “Identität Überfremdung stoppen!”. Disponível em http:/ / www.npd.de/identitaet/. Acesso em 05 de dezembro de 2014.

PARLAMENTO EUROPEU. "Results of the 2014 European Elections". Disponível em http:/ / www.europarl.europa.eu/elections2014results/en/seats-member-state-absolut.html. Acesso em 05 de dezembro de 2014.

\section{REISSMANN, Ole. Fusion mit DVU: NPD schmiedet Pakt der}

Rechtsextremen. Spiegel Online. 15 de janeiro de 2011. Disponível em http:/ / www.spiegel.de/politik/deutschland/fusion-mit-dvu-npd-schmiedetpakt-der-rechtsextremen-a-739583.html. Acesso em 10 de dezembro de 2014.

\section{REPÚBLICA FEDERAL DA ALEMANHA. Lei Fundamental da República} Federal da Alemanha. Disponível em http:// www.brasil.diplo.de/contentblob/3254212/Daten/1330556/Constituica oPortugues_PDF.pdf. Acesso em 05 de dezembro de 2014.

ROSSTEUTSCHER, Sigrid; FAAS, Thorsten; ARZHEIMER,Kai. Voters and Voting in Multilevel Systems - An Introduction. German Politics, vol.24, no.1, 2015.

RYDGREN, Jens. Is extreme right-wing populism contagious? Explaining the emergence of a new party family. European Journal of Political Research, no.44, p.413-437, 2005.

STEUDEL, Nastassja. Second attempt to ban neo-Nazi NPD under way. Deutsche Welle, 21 de junho de 2014. Disponível em http:/ / www.dw.de/second-attempt-to-ban-neo-nazi-npd-under-way/a17726217. Acesso em 05 de dezembro de 2014.

THE ECONOMIST. German election results - Who's in the Haus?. 23/09/2013. Disponível em http:// www.economist.com/blogs/charlemagne/2013/09/german-electionresults. Acesso em 02 de abril de 2015.

THE ECONOMIST. German Politics - Defeat on the Elbe. 21/02/2015. Disponível em http:/ / www.economist.com/news/europe/21644208-electionhamburg-underlines-domestic-weakness-angela-merkel-defeat-elbe. Acesso em 02 de abril de 2015.

TOSTES, Ana Paula. Razões da Intolerância na Europa Integrada. DADOS Revista de Ciências Sociais, Rio de Janeiro, vol. 52, no.2, p.335-376, 2009. 
93 | InterAção

TOSTES, Ana Paula. Euroskepticism in European National Elections: The Rise of Voter Support for New Radical Right Parties. Brazilian Political Science Review, vol 5, no.1, p.77-104, 2011.

WAHLRECHT. “Ergebnisse der Bundestagswahlen”. Disponível em http:/ / www.wahlrecht.de/ergebnisse/bundestag.htm. Acesso em 05 de dezembro de 2014.

WILDE, Wulf. Far-right successor to NPD waits in the wings. Deutsche Welle. 15 de dezembro de 2012. Disponível em http:/ / www.dw.de/ far-rightsuccessor-to-npd-waits-in-the-wings/a-16456578. Acesso em 11 de dezembro de 2014.

WITTROCK, Philipp; DIEKMANN, Florian; HEBEL, Christina. Die Rechte: Neue Rechtspartei will NPD ersetzen. Spiegel Online, 27 de julho de 2012. Disponível em http:/ / www.spiegel.de/politik/deutschland/neue-neonazipartei-die-rechte-macht-rechtsextremer-npd-konkurrenz-a-846528.html. Acesso em 12 de dezembro de 2014. 